\title{
End-tidal concentration of sevoflurane for preventing rocuronium-induced withdrawal of the arm in pediatric patients
}

\author{
Jong Hoon Yeom, Yong Oh Kim, Jae Min Lee, and Woo Jae Jeon \\ Department of Anesthesiology and Pain Medicine, Hanyang University Guri Hospital, Guri, Korea
}

Background: During induction of general anesthesia, the intravenous injection of rocuronium is often associated with withdrawal movement of the arm due to pain, and this abrupt withdrawal may result in dislodgement of the venous catheter, injury, or inadequate injection of rocuronium. We performed this study to evaluate the 50 and $95 \%$ effective endtidal concentrations of sevoflurane ( $\left.\mathrm{ET}_{\mathrm{sev}}\right)$ for preventing rocuronium-induced withdrawal of the arm.

Methods: We conducted a prospective double-blind study in 31 pediatric patients. After free flow of lactated Ringer's IV fluid was confirmed, anesthesia was induced in the patients by using $2.5 \%$ thiopental sodium $(4 \mathrm{mg} / \mathrm{kg})$ and sevoflurane (4 vol\%) with $6 \mathrm{~L} / \mathrm{min}$ of oxygen. When the target ETsev was reached, preservative-free $1 \%$ lidocaine $(1.5 \mathrm{mg} / \mathrm{kg})$ was intravenously injected during manual venous occlusion and rocuronium $(0.6 \mathrm{mg} / \mathrm{kg})$ was injected after lidocaine injection under free-flow intravenous fluid. A nurse who was an investigator and was blinded to the ETsev injected the rocuronium. The nurse evaluated the response.

Results: Non-withdrawal movement was observed in 5 out of 11 patients with ETsev $3.0 \mathrm{vol} \%$ and in 5 out of 6 patients with ETsev 3.5 vol\%. By Dixon's up-and-down method, the 50\% effective concentration $\left(\mathrm{EC}_{50}\right)$ of sevoflurane for nonwithdrawal movement at rocuronium injection was $3.1 \pm 0.4 \mathrm{vol} \%$. A logistic regression curve of the probability of nonwithdrawal movements showed that the $50 \%$ effective ETsev for abolishing withdrawal movement at rocuronium injection was 2.9 vol\% (95\% confidence interval [CI] 2.4-3.8 vol\%) and the 95\% effective ETsev was 4.3 vol\% (95\% CI 3.6-9.8 vol\%).

Conclusions: This study showed that the 50 and 95\% effective ETsev that prevent withdrawal movement at rocuronium injection are 2.9 and 4.3 vol\%, respectively. (Korean J Anesthesiol 2014; 66: 274-277)

Key Words: Pain, Rocuronium, Sevoflurane, Withdrawal.

Received: July 22, 2013. Revised: 1st, September 24, 2013; 2nd, October 1, 2013. Accepted: October 5, 2013.

Corresponding author: Jong Hoon Yeom, M.D., Department of Anesthesiology and Pain Medicine, Hanyang University Guri Hospital, 249-1, Kyomun-dong, Guri 471-701, Korea. Tel: 82-31-560-2390, Fax: 82-31-563-1731, E-mail: yeomjh@hanyang.ac.kr

(c) This is an open-access article distributed under the terms of the Creative Commons Attribution Non-Commercial License (http:// creativecommons.org/licenses/by-nc/3.0/), which permits unrestricted non-commercial use, distribution, and reproduction in any medium, provided the original work is properly cited. 


\section{Introduction}

Rocuronium is a widely used non-depolarizing neuromuscular blocking drug that is structurally related to vecuronium. It is characterized by a rapid onset of action and an intermediate duration. During induction of general anesthesia, the intravenous (IV) injection of rocuronium is often associated with the withdrawal movement of the arm into which the drug is injected due to pain. Abrupt arm withdrawal during rocuronium injection may result in dislodgement of the venous catheter, injury, or inadequate injection of rocuronium.

Several techniques have been suggested for reducing or preventing the pain, with varying success. The most popular methods often involve pretreatment with drugs, but no method is currently available to prevent such pain completely [1-7]. The injection pain of rocuronium could be relieved by using inhaled anesthesia immediately after the IV induction or by using an inhaled induction of anesthesia and allowing adequate anesthetic depth. However, no previous study investigated the end-tidal concentration of sevoflurane $\left(\mathrm{ET}_{\mathrm{sev}}\right)$ used during induction for preventing arm withdrawal associated with the injection of rocuronium.

The purpose of this study was to evaluate the 50 and $95 \%$ effective $\mathrm{ET}_{\text {sev }}$ for prevention of rocuronium-induced withdrawal movements.

\section{Materials and Methods}

The protocol of this study was approved by the Institutional Ethical Committee of our Hospital (2013-44) and informed parental consent was obtained. We studied 31 patients who were American Society of Anesthesiologists physical status I, aged 1-6 years, weighed less than $30 \mathrm{~kg}$, and were undergoing general anesthesia for elective surgery. We excluded patients who had a history of neurological deficits, allergies to lidocaine, thiopental, rocuronium or asthma, and those who had received analgesics or sedatives within the previous $24 \mathrm{~h}$.

Medication was not given before the induction of anesthesia. Before arriving in the operating room, we required that a 22-gauge cannula had been placed in the patient's largest vein on the dorsum of the hand in the ward. All patients were monitored using an electrocardiogram, pulse oximetry, and noninvasive blood pressure. After free flow of lactated Ringer's IV fluid was confirmed, the patient underwent anesthesia induction by using $2.5 \%$ thiopental sodium ( $4 \mathrm{mg} / \mathrm{kg}$ ) and sevoflurane (4 vol\%) with $6 \mathrm{~L} / \mathrm{min}$ of oxygen. When the target $\mathrm{ET}_{\mathrm{sev}}$ was reached, the heart rate (HR) and mean arterial pressure (MAP) were recorded. Further, preservative-free $1 \%$ lidocaine $(1.5 \mathrm{mg} / \mathrm{kg})$ was intravenously injected during manual occlusion of the IV fluid line to stabilize the hemodynamic response due to endotracheal intubation, and rocuronium $(0.6 \mathrm{mg} / \mathrm{kg})$ was injected imme- diately after lidocaine injection under free flow of IV fluid. A nurse who was an investigator and was blinded to ET sev injected the rocuronium. After the nurse evaluated the response, the maximum HR during $30 \mathrm{~s}$ and the MAP after rocuronium injection were recorded. The study was terminated at this point, and the anesthetic was continued at the discretion of an attending anesthesiologist. The ET $\mathrm{E}_{\mathrm{sev}}$ was monitored by using the Primus Infinity ${ }^{\circledR}$ Empowered (Dräger, Drägerwerk AG \& Co., Lübeck, Germany).

Patient data are presented as the mean \pm SD. We studied 31 patients on the basis of Dixon's up-and-down method, and nine pairs of withdrawal and non-withdrawal movements were collected for statistical analysis with this method [8]. The 50\% effective concentration $\left(\mathrm{EC}_{50}\right)$ by Dixon's up-and-down method was defined as the mean of the crossover end-tidal concentrations. The withdrawal and non-withdrawal movement sequences were analyzed by the probit test, which enabled us to derive the ETsev for non-withdrawal movement with $95 \%$ confidence limits of the mean. The patient characteristics (comparison between the withdrawal and non-withdrawal movement patients at rocuronium injection) were evaluated by using chi-square analysis and the Mann-Whitney $U$ test, when appropriate. The MAP and HR before and after rocuronium injection was compared by using the Wilcoxon signed-rank test. The differences in the MAP and HR before and after rocuronium injection between the withdrawal and non-withdrawal movement patients were analyzed by the Mann-Whitney $U$ test because of non-normal distribution. The differences were considered statistically significant when $\mathrm{P}<0.05$. SPSS package (version 19.0, SPSS Inc., Chicago, IL, USA) was used for statistical analysis.

\section{Results}

The sequences of withdrawal and non-withdrawal movements are shown in Fig. 1. Non-withdrawal movement was observed in 5 out of 11 patients with $\mathrm{ET}_{\text {sev }} 3.0$ vol\% and in 5 out of 6 patients with $\mathrm{ET}_{\mathrm{sev}} 3.5 \mathrm{vol} \%$. By Dixon's up-and-down method, the $\mathrm{EC}_{50}$ of sevoflurane for non-withdrawal movement at rocuronium injection was $3.1 \pm 0.4 \mathrm{vol} \%$. A logistic regression curve of the probability of non-withdrawal movement showed that the $50 \%$ effective $\mathrm{ET}_{\mathrm{sev}}$ for abolishing withdrawal movement at rocuronium injection was 2.9 vol\% (95\% confidence interval [CI] 2.4-3.8 vol\%), and the $95 \%$ effective $\mathrm{ET}_{\text {sev }}$ was 4.3 vol\% (95\% CI 3.6-9.8 vol\%). During the study, hemodynamic stability within $30 \%$ of the pre-operative values was maintained in all patients.

The patient profiles in the withdrawal and non-withdrawal movement groups are compared in Table 1. The mean ETsev in non-withdrawal movement patients was statistically higher than that of withdrawal movement patients (3.1 vs $2.6 \mathrm{vol} \%, \mathrm{P}=0.01$ ). 


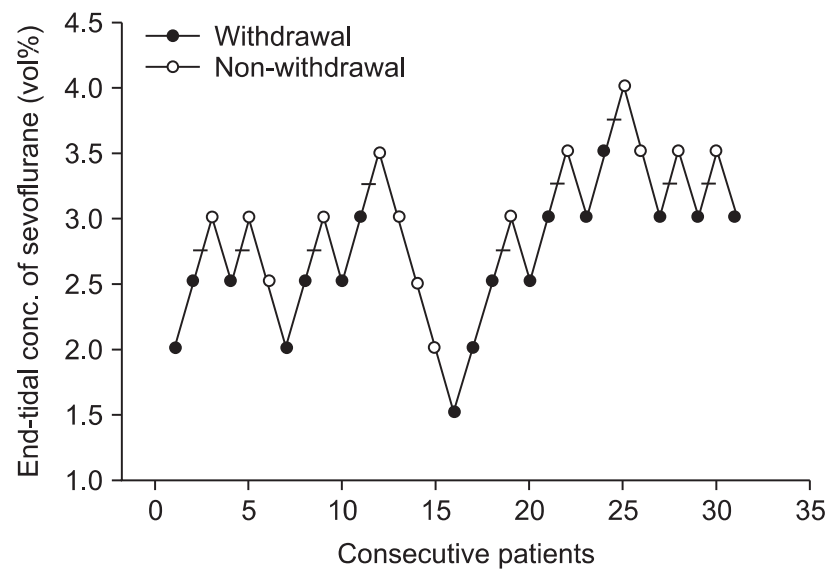

Fig. 1. Data of consecutive withdrawal and non-withdrawal movement over predetermined end-tidal concentration of sevoflurane (with an initial predetermined concentration of $2.0 \mathrm{vol} \%$ for the first patient). We collected nine pairs of withdrawal and non-withdrawal movement sequences for statistical analysis with Dixon's up-and-down method. The end-tidal concentration of sevoflurane for abolishing withdrawal movement in 50\% of patients was $3.1 \pm 0.4 \mathrm{vol} \%$.

A comparison of the hemodynamic values of withdrawal and non-withdrawal movement patients is shown in Table 2. The HR was significantly higher after rocuronium injection compared to before rocuronium injection in both withdrawal and non-withdrawal movement patients. However, the differences in MAP and HR were not statistically significant between withdrawal and non-withdrawal movement patients.

\section{Discussion}

In previous studies, the incidence of withdrawal movement by rocuronium injection without pretreatment was 22 to $84 \%$ [3-7,9]. Age and sex differences regarding the incidence of withdrawal are controversial $[2,5,10]$. A pretreatment intervention for preventing rocuronium-induced withdrawal movement may increase cost to the patients and may involve the risk of developing adverse effects. However, generalized movement by rocuronium-induced pain cause pulmonary aspiration [11] and rocuronium-induced pain similar to propofol-induced pain during induction may cause bronchospasm, asthma, or myocardial ischemia attack [12].

Abrupt arm withdrawal during rocuronium injection may result in dislodgement of the venous catheter, injury, or inadequate injection of rocuronium. Therefore, caution should be taken to prevent its occurrence. Various drugs have been used in an attempt to prevent, but not completely eliminate, rocuronium-induced withdrawal movement, with varying success (3093\%) [1-7]. Other methods have been proposed for preventing withdrawal movement, such as the use of midazolam, fentanyl, lidocaine, tramadol, ondansetron, ketorolac, or a combination
Table 1. Patient Profiles

\begin{tabular}{lcc}
\hline & Withdrawal & Non-withdrawal \\
\hline Number of patients & 17 & 14 \\
Sex (M/F) & $8 / 9$ & $8 / 6$ \\
Age (yr) & $4.6 \pm 1.5$ & $4.4 \pm 1.4$ \\
Body weight $(\mathrm{kg})$ & $19.7 \pm 4.5$ & $19.0 \pm 1.4$ \\
Height $(\mathrm{cm})$ & $109.6 \pm 9.9$ & $107.0 \pm 11.8$ \\
ET & $2.6 \pm 0.6$ & $3.1 \pm 0.5$ \\
\hline
\end{tabular}

The profiles of withdrawal and non-withdrawal movement patients at rocuronium injection. Values are expressed as the mean $\pm \mathrm{SD}$ or as a number. $\mathrm{ET}_{\text {sev: }}$ end-tidal concentration of sevoflurane. ${ }^{*} \mathrm{P}=0.01$ between groups.

Table 2. Hemodynamic Profiles

\begin{tabular}{lccc}
\hline & & Withdrawal $(\mathrm{n}=17)$ & Non-withdrawal $(\mathrm{n}=14)$ \\
\hline MAP (mmHg) & T1 & $78.9 \pm 9.5$ & $78.9 \pm 14.1$ \\
& T2 & $79.5 \pm 10.2$ & $74.1 \pm 8.6$ \\
HR (beats/min) & T1 & $108.2 \pm 16.4$ & $101.4 \pm 11.1$ \\
& T2 & $123.8 \pm 17.0^{*}$ & $112.9 \pm 12.6^{*}$ \\
\hline
\end{tabular}

Hemodynamic profiles before and after rocuronium injection in withdrawal and non-withdrawal movement patients. Values are expressed as the mean \pm SD. T1: time before rocuronium injection, T2: time after rocuronium injection, MAP: mean arterial pressure, HR: heart rate. $* \mathrm{P}<0.05$ between $\mathrm{T} 1$ and $\mathrm{T} 2$.

of lidocaine and ketorolac pretreatment [3-7,9,13]. Among ondansetron, lidocaine, tramadol, and fentanyl, lidocaine was the most effective drug [4], and the effect of lidocaine in attenuating pain was dose-dependent [3]. Further, pretreatment with a small dose of ketamine $(0.2 \mathrm{mg} / \mathrm{kg})$ reduced rocuronium-induced withdrawal movement in pediatric patients [5]. However, these techniques required time-consuming procedures and might have side effects or contraindications.

The mechanism of rocuronium-induced pain has not been elucidated, but several theories have been proposed, including relatively low $\mathrm{pH}$ or the release of local mediators $[3,14,15]$. The IV injection of normal saline buffered to a $\mathrm{pH}$ of 4 was not associated with pain; therefore, low $\mathrm{pH}$ is not the major cause of this phenomenon [16]. Several studies suggested that the release of local mediators such as histamine, which directly activates venous nociceptors, may be the total or partial cause of pain $[5,17]$. However, histamine is an unlikely candidate because neither erythema nor warmth was reported in the surrounding tissue or was observed in awake patients [16], although thiopental sodium and rocuronium injection in rapid sequence caused skin erythema at the site of injection [5]. Other mediators such as the kininogen cascade may be involved because the nature of the pain with rocuronium and propofol is similar: each appear immediately during IV injection, the duration is short, and the intensity decreases with subsequent injection. Therefore, mediators that are related to propofol-induced pain may also be in- 
volved in rocuronium-induced pain [16]. Although correlations were not found between the pain rating and mediator release, a significant correlation was found between the pain rating and the axon-reflex vasodilatation; thus, the pain-producing effect of rocuronium can be attributed to the direct activation of Cnociceptors [18].

In this study, we used sevoflurane with the goal of determining the $\mathrm{ET}_{\text {sev }}$ for eliminating arm withdrawal movement irrespective of the causes. Our results show that the 95\% effective $\mathrm{ET}_{\text {sev }}$ that abolishes arm withdrawal movement by rocuronium injected immediately after lidocaine injection $(1.5 \mathrm{mg} / \mathrm{kg})$ is 4.3 vol\%.

This study has two limitations arising from the design of the study. Lidocaine $(1.5 \mathrm{mg} / \mathrm{kg})$ with manual venous occlusion was used immediately before injection of rocuronium to stabilize the hemodynamic response due to endotracheal intubation by blunting the activation of the sympathetic nerve system. The use of lidocaine at that time in the procedure may have attenuated rocuronium-induced pain by heightening the pain threshold. The other limitation is the time lag between lidocaine and rocuronium injection when the $\mathrm{ET}_{\text {sev }}$ reached the target concentration. Although the $\mathrm{ET}_{\text {sev }}$ tended to increase with the time lapse during manual ventilation, the time lag was very short.

In conclusion, the 50 and $95 \%$ effective $\mathrm{ET}_{\text {sev }}$ that prevented withdrawal movement at rocuronium injection were 2.9 and 4.3 vol\%, respectively. Considering these ETsev values during induction may help to provide a simple and reliable means for reducing the incidence and severity of rocuronium-induced movement without adverse hemodynamic changes.

\section{References}

1. Borgeat A, Kwiatkowski D, Ruetsch YA. Spontaneous movements associated with rocuronium injection: the effects of prior administration of fentanyl. J Clin Anesth 1997; 9: 650-2.

2. Shevchenko Y, Jocson JC, McRae VA, Stayer SA, Schwartz RE, Rehman M, et al. The use of lidocaine for preventing the withdrawal associated with the injection of rocuronium in children and adolescents. Anesth Analg 1999; 88: 746-8.

3. Cheong KF, Wong WH. Pain on injection of rocuronium: influence of two doses of lidocaine pretreatment. Br J Anaesth 2000; 84: 106-7.

4. Memiş D, Turan A, Karamanlioğlu B, Süt N, Pamukçu Z. The prevention of pain from injection of rocuronium by ondansetron, lidocaine, tramadol, and fentanyl. Anesth Analg 2002; 94: 1517-20.

5. Liou JT, Hsu JC, Liu FC, Ching-Wah Sum D, Lui PW. Pretreatment with small-dose ketamine reduces withdrawal movements associated with injection of rocuronium in pediatric patients. Anesth Analg 2003; 97: 1294-7.

6. Kim JY, Kim JY, Kim YB, Kwak HJ. Pretreatment with remifentanil to prevent withdrawal after rocuronium in children. Br J Anaesth 2007; 98: 120-3.

7. Jeon Y, Ha JH, Lee JE, Lee HC, Ryu TH, Kwak KH. Rocuronium-induced withdrawal movement: influence of ketorolac or a combination of lidocaine and ketorolac pretreatment. Korean J Anesthesiol 2013; 64: 25-8.

8. Dixon WJ. Staircase bioassay: the up-and-down method. Neurosci Biobehav Rev 1991; 15: 47-50.

9. Reddy MS, Chen FG, Ng HP. Effect of ondansetron pretreatment on pain after rocuronium and propofol injection: a randomised, doubleblind controlled comparison with lidocaine. Anaesthesia 2001; 56: 902-5.

10. Mencke T, Beerhalter U, Fuchs-Buder T. Spontaneous movements, local reactions and pain on injection of rocuronium. A comparison between female and male patients. Acta Anaesthesiol Scand 2001; 45: 1002-5.

11. Lui JT, Huang SJ, Yang CY, Hsu JC, Lui PW. Rocuronium-induced generalized spontaneous movements cause pulmonary aspiration. Chang Gung Med J 2002; 25: 617-20.

12. Morishima T, Sobue K, Arima H, Tanaka S, So M, Ando H, et al. Profound pain due to propofol injection triggered myocardial ischemia in a patient with a suspected pheochromocytoma. Anesth Analg 2003; 96: 631.

13. Ruetsch YA, Borgeat A. Withdrawal movements associated with the injection of rocuronium. Anesth Analg 2000; 90: 227-8.

14. Ti LK, Dhara SS. Vecuronium, like rocuronium, causes pain on injection. Br J Anaesth 1998; 81: 487.

15. Klement W, Arndt JO. Pain on i.v. injection of some anaesthetic agents is evoked by the unphysiological osmolality or pH of their formulations. Br J Anaesth 1991; 66: 189-95.

16. Borgeat A, Kwiatkowski D. Spontaneous movements associated with rocuronium: is pain on injection the cause? Br J Anaesth 1997; 79: $382-$ 3.

17. Kindgen-Milles D, Klement W, Arndt JO. The nociceptive systems of skin, paravascular tissue and hand veins of humans and their sensitivity to bradykinin. Neurosci Lett 1994; 181:39-42.

18. Blunk JA, Seifert F, Schmelz M, Reeh PW, Koppert W. Injection pain of rocuronium and vecuronium is evoked by direct activation of nociceptive nerve endings. Eur J Anaesthesiol 2003; 20: 245-53. 